\title{
Zygomaticus Minor Muscle
}

National Cancer Institute

\section{Source}

National Cancer Institute. Zygomaticus Minor Muscle. NCI Thesaurus. Code C53184.

A muscle of facial expression that originates on the malar bone and inserts into the skin and muscle of the upper lip, with innervation by the facial nerve, which functions to elevate and evert the upper lip. 